\title{
NOMENCLATURE AT SYDNEY
}

Edward G. Voss ${ }^{1}$

"For the right names of flowers are yet in
Heaven. God make gardeners better nomencla-
tors." Christopher Smart in Jubilate Agno, ca.
1760.

Following the Edinburgh (1964) and Seattle (1969) International Botanical Congresses, my predecessor as Rapporteur-général, Frans Stafleu, presented in Taxon (13: 273-282; 19: 36-42) light and rather personal reports conveying some of the spirit as well as the substance of what the Nomenclature Section accomplished-a tradition here resumed. A tabulation of specific actions (including disposition of published proposals) appeared in the November 1981 issue of Taxon, and several committee reports will appear in the May 1982 issue. A full report, prepared largely by Werner Greuter, will follow. But did we really do anything to make better nomenclators of gardeners - or taxonomists? Since the time of Carl Linnaeus, whose nomenclatural endeavors are better known than anything said on the subject by his contemporary, the eccentric Christopher Smart (who penned the work quoted above while incarcerated in a British insane asylum), Smart's cry of despair and plea for divine guidance in nomenclature have often been thought if not explicitly stated.

The Code never seems to offer enough guidance (or the right guidance) to please everyone, so the nomenclators of the world gathered once again at Sydney for $41 / 2$ days of deliberations, August 17-21, 1981, immediately preceding the main sessions of the XIII International Botanical Congress. With 152 registered members of the Nomenclature Section and 210 proposals for amendment of the Code assembled in the Synopsis (plus several late proposals from the floor), it is not surprising that discussion filled, as always, all available time. The pace at which proposals were acted upon (or referred to a committee) quickened perceptibly as the week drew closer to its end. The ninth half-day session was even able to adjourn a full hour early, thanks to the skillful and experienced guidance of Reed Rollins, whose first service as president of the Section was at Edinburgh in 1964. Relieving him for some of the sessions were vice presidents Hansjörg Eichler and Desmond Meikle. About 45\% of the proposals were either accepted or referred to the editorial committee, a slightly higher percentage than usual. Almost the same number were rejected, but many of these were understood to be referred, along with some others, for consideration by four special committees to be appointed by the General Committee with a charge to report to the next Congress on matters of lectotypification, orthography, effective publication, and valid publication. Had the Section fully debated these topics, we might still be in Sydney (indeed a more pleasant place than the northern hemisphere to be this time of year!). As it was, most proposals heavily rejected by the mail vote were even quite fully discussed (or cussed) on the floor.

All this helps to make clear that attendance at the nomenclature sessions does serve to make all of us better nomenclators, for there is no more educational experience than hearing (and participating in) discussions on what the Code says, what it means, what it ought to say, and what it ought not to say. Members of the Section included a full range of experience, from graduate students to botanists with memories of several previous Congresses. It is this fully democratic opportunity to make and discuss proposals, to explore their implications for several branches of taxonomy and bibliography, and to meet one's colleagues that justifies the regular gathering of these sessions (in which any Congress registrant is entitled to participate). Rotation of Congresses among different countries encourages diverse geographic representation; this first Congress in the southern hemisphere was particularly noteworthy in this respect. The Section included a number of "old faithfuls" whose familiar faces and nomenclatural oratory lend an aura of continuity, even stability, to the proceedings. But there were also so many Australian and New Zealand botanists (for whom attendance at previous Congresses was

1 Herbarium, North University Bldg., University of Michigan, Ann Arbor, MI 48109, U.S.A. 
especially difficult) that all of us from the "outbacks" of the world (such as Europe and the Americas) were overwhelmed not only by the hospitality and cordiality of our Antipodean colleagues but also by the opportunity to learn of their taxonomic and nomenclatural activities (not to mention, during later Congress field trips, their "curious and diverse" flora). Alas, a large number of plant systematists whose death had occurred since 1975 were not with us. Among the names read before a minute of silence at the opening session were such nomenclatural stalwarts of past years as C. E. B. Bonner, A. A. Bullock, James Dandy, Peter Florschütz, Mrs. Sprague, H. E. Moore, J. M. Schopf, Roger de Vilmorin, and Luella Weresub.

One of the hottest debates at the Leningrad Congress in 1975 centered upon a proposal from the floor by V. P. Botschantzev concerning transliteration of authors' names from non-Roman alphabets. The controversial matter was referred to a special committee to be set up by the General Committee and whose detailed report appeared in the February 1981 number of Taxon. The committee (Dan Nicolson, convener) proposed a brief new Recommendation, to follow Article 46. This was accepted at Sydney, almost miraculously without discussion and without opposition, demonstrating the wisdom of referring complex matters to a competent committee whose collective judgment after thorough deliberation may be trusted. Likewise, the Leningrad Congress referred a large number of proposals on fungi (especially those associated with Art. 59) back to the Committee for Fungi and Lichens, which also considered proposals emanating from the Nomenclature Secretariat of the International Mycological Congresses. The Committee's report (Taxon 30: 472) thus culminated nine years of effort; at Sydney every proposal recommended by the Committee was accepted and every proposal rejected by the Committee was rejected-with little or no discussion. There was even final agreement on the proposal to amend starting-points for fungi as endorsed by the Committee.

Additional testimony to the committee method involved the typification of generic names, another topic referred at Leningrad to a special ad hoc committee, for which John McNeill served as secretary. The solution preferred by the committee (props. 111, 112, 113, Taxon 30 : 205) was accepted, providing the new idea that the type of a generic name is actually a specimen, although it may generally be referred to by the name of the species of which that specimen is the type. Traditional usage and past designations are thus largely maintained. Preference is given to the type of a name cited in the protologue.

At Leningrad, nomenclature began with consideration of orthography, a subject often treated very hastily in the closing session because the Articles and Recommendations come at the end of the Code. At Sydney, for similar reasons, the sessions began with Appendix I, on hybrids. Although the Committee for Hybrids had not formally made proposals, the revision of Appendix I offered by its secretary, Peter Yeo, and endorsed by its chairman and others concerned, was accepted. Except for the word nothotaxon, there is little really new, but the appendix is arranged more logically and numerous minor improvements are made.

The subject of autonyms can always be counted upon for a spirited discussion, during which we can rely upon presentation of a Heracleum example. The special committee authorized by the previous Congress came in with a quite divided report and all major proposals were at first rejected on Tuesday morning even though a show of hands had indicated favor for making some change. In the afternoon a proposal was readily accepted that consisted of Art. 19 Prop. $C$ plus a provision offered by Vincent Demoulin, that an autonym has priority over the name that created it. Thus, an exception to Art. $\mathbf{5 7 . 2}$ was instituted, so that if a name is needed at a rank for which an applicable autonym exists, the epithet of the autonym must be used in a new combination and not the epithet of the same rank (and date) in the name that caused the autonym to be established. [If one merges Planta delta including its var. delta and var. gamma with $P$. alpha, and wishes to recognize it now at varietal rank, it must be called $P$. alpha var. delta and not $P$. alpha var. gamma.] Although autonyms as such still have no author citations, they have (like hybrids over the years) now gained some respectability as names and the statement adopted at Seattle that they have no priority is deleted. The autonym rules were also amended to apply at all ranks of subdivision of a genus, not merely those (subgenus and section) now specified in Article 22.2.

Another topic almost invariably discussed at every Nomenclature Section with vigorous arguments (seldom if ever new), both pro and con, is that of stabilization of specific names. The committee appointed to consider once again this eternal topic did not function, but indi- 
vidual proposals had been made in order to assure some attention. As amended from the floor to apply only to "names of species of major economic importance" the principle of nomina specifica conservanda was at last accepted, much to the pleasure of those who have fought for so long, and to the horror of others. The vote was close, under the $60 \%$ rule in use since the Edinburgh Congress, but when the cards were counted the amended proposal carried by $60.9 \%$. Species names will go through the same committees as other conservation proposals. The General Committee is to draw up guidelines for preparation of suitably documented proposals, to ease the work of preparers, committees, and editors. The Standing Committee on Stabilization, first established at Edinburgh, was allowed to expire.

A close vote in the other direction involved the similarly perennial matter of substituting "phylum" for "division." It was a proposal that failed to receive a $60 \%$ card vote while having a simple majority (228 yes, 177 no). Several points apparently favored the opposition, including the fact that neither the zoological nor bacteriological codes actually mention any rank at that level ("phylum" being merely a "bad habit," as it was termed, of the zoologists, to which we were being asked to make our Code conform), the historic use of both "phylum" and "division" by some authors the status of whose names would have to be made clear, and the available option under Article 4 to intercalate the rank of phylum anyway. So much lively discussion over a single word! But a petition to reconsider on the last day was soundly rejected.

Moments of drama arose not only from close votes and tabulation of cards but also from bits of unsuppressed eloquence that moved delegates in a way that no cold facts could do. Dick Brummitt made a stirring "appeal from the heart" to support Art. 19 Prop. B, which was accepted on a card vote, allowing use of the subfamily name Papilionoideae under the unique familial nomenclature permitted for the legumes. When William Stearn defended the scholarly sprunerianus and hasslerianus-one more long-time cause célèbre-by noting that "too late to change" might apply to drunkards, drug addicts, and the extremely aged-none of whom appeared to be present-what could the majority do but vote (251 to 150) for the change from spruneranus and hassleranus? So an orthography preferred by the Code since 1905 (though not always followed) is finally altered.

A further rule for many years a source of unhappiness is Article 69, which has been both defended as a necessary escape route and attacked as subversive to the type method. In 1975 it survived the deletion of adjoining Articles 70 and 71, but was remodeled to reflect more clearly the type method. Clarity was added in 1981 by defining further the meaning of a "rejected name"; Art. 69 Prop. C was however amended to change "must" to "may," thus removing the absolute obligation to reject a nomen ambiguum. One may now propose to reject such a name, and the editorial footnote to Article 69 inserted in the Leningrad Code was formally accepted as the procedure to be followed.

All in all, the new edition of the Code will not look very much different from the current one, in which the most conspicuous alteration was application of a new pseudo-decimal system that makes reference to passages very much easier. Even the more significant changes adopted at Sydney can be rather easily incorporated. New appendices will ultimately be needed for nomina specifica conservanda (none of which can be official until after 1987) and nomina ambigua formally rejected under Article 69. There were several things the Section did not do; for example, living types were not reinstituted (for fungi or anything else), a separate paleobotanical appendix was not authorized, no new committee on conserved specific names was established, and Art Cronquist did not sing the Volga Boatman (or anything else).

Having concluded my emergency tenure as Rapporteur, I can only reiterate how essential the hard work of a great many people is to smooth operation of the Nomenclature Section and to maintaining the usual genial good spirits of its members. The gentle guidance of the president and vice presidents through the sessions is easily observed. Behind the scenes, Hansjörg Eichler had worked closely with the Executive Secretary of the Congress, John Cram, and others in making the local arrangements. We had an ample, conveniently located meeting room with microphones and tape-recording facilities for all sessions, persons to collect written comments from speakers, tea and lunch facilities in the same building (Stephen Roberts Theatre on the University of Sydney campus), and all other necessary logistic support. The hard wooden seats so essential to keep everyone awake served their purpose well. Tony Orchard came up from Hobart to act as recorder and proved to be not so much a Tasmanian devil as 
what in northern latitudes at least would more aptly be called a beaver, the very symbol of industry and hard work, which is precisely what was needed to keep a full acount of every action finally taken, amid a forest of verbiage, by the Section. Werner Greuter, vice rapporteur, participated fully in preparation of the Synopsis of Proposals and had his papers-not to mention his mind-perfectly organized so as to keep us always clear about what we were doing (a demand more than once made from the floor). As the new Rapporteur he will steer the 1987 sessions, and as secretary of the Editorial Committee (which is meeting in Berlin in March of 1982) he is making every effort to have the new Code available as promptly as possible. It was a shame to abandon after only 11 card votes the elegant wooden ballot-boxes that had been made by David Bedford, whose greater claim to glory lies in the arrangements he made for the traditional Nomenclature/IAPT dinner, which was held on Wednesday evening in the Holme Building on the Sydney campus. A large attendance of members and friends in comfortable facilities after an excellent meal was regaled by Desmond Meikle who served as master of ceremonies, recognizing the secretaries and chairmen of committees and others whose steady labors in the vineyards of nomenclature are essential in the years between Congresses. Who will soon forget Desmond's vision of a dancing cabaret of nomina nuda and other delights?

The list of institutional votes as published at the end of the Report of the Nomenclature Section in the Proceedings of the Leningrad Congress was slightly modified, over the year and a half preceding the Sydney Congress, by consultation between the General Committee, the Bureau of Nomenclature, and the rapporteurs. At a meeting of the Bureau immediately before the first nomenclature session a few further requests for alterations were considered, but the Bureau took the position that it would only add institutions represented at the Congress but previously without a vote and not at that point alter the number of votes for any. The whole matter of institutional votes is a very difficult (even distasteful) one to administer; however, Division III of the Code assigns the task to the Bureau and the General Committee and authorizes a scale of 1-7; but it does not define "institution." At the last session, a motion to increase the maximum institutional vote to 10 was defeated, primarily on the grounds that it could lead to a loss of balance between institutional and personal votes. Instead, the responsible bodies were instructed to define "institution" comprehensively, so that no one university, research institute, museum, etc., will receive more than 7 votes regardless of its internal structure or divisions. Even so, it will not be easy to rank institutions ranging from one active taxonomist to 60 , engaging in a diversity of types of research and publication, participating in indexing or other nomenclatural services, caring for important collections, working on few or many plant groups, and offering other evidences of their taxonomic activity.

Finally, it is my pleasant duty to acknowledge financial support from the National Science Foundation of the United States (Grant No. DEB-8008083) which has aided in my preparation of nomenclatural documents and necessary bibliographical investigations. 